\title{
B CELL TOLL-LIKE RECEPTORS WITH RESPECT TO THE PATHOGENESIS OF SJŐGREN'S SYNDROME
}

\author{
Irena Berglová ${ }^{1,2}$, Jan Krejsek${ }^{1}$, Martina Koláčková ${ }^{1}$, Radovan Slezák ${ }^{2}$
}

Charles University in Prague, Faculty of Medicine and University Hospital Hradec Králové, Czech Republic: Department of Clinical Immunology and Allergology ${ }^{1}$; Department of Dentistry ${ }^{2}$

\begin{abstract}
Summary: Sjőgren's syndrome (SS) is a chronic autoimmune immunopathological disease of unknown aetiology. It is characterized by focal lymphocyte infiltration and inflammation in exocrinne glands, involving especially salivary and lacrimal glands. Hypofunction of the glands leads to the decreased glandular secretion together with impaired production of saliva and tears, resulting in dryness of the mouth and eyes (xerostomia and xerophthalmia, respectively). Some of the studies have suggested that Toll-like receptors and B cells play a pivotal role in the pathogenesis of autoimmune diseases such as systemic lupus erythematosus, rheumatoid arthritis and SS etc. Stimulation of B cells via the TLRs pathway leads to several important changes including increase in antibody production, differentiation to plasma cells, cytokine production and up-regulation of molecules essential for antigen presentation to (autoreactive) T cells. Experimental data support the idea that co-engagement of BCR and TLR might be sufficient for B cell activation and lead to the failure of tolerance. In human naive B cells, most TLRs are expressed at very low or undetectable level, but expression of TLR 7 and 9 is rapidly induced by B cell receptor triggering. This review will focus on the possible role of B cells and TLRs signaling in the pathogenesis of SS.
\end{abstract}

Key words: Sjögren's syndrome; Pathogenesis; B cell; TLR; Activation

\section{Introduction}

SS is an inflammatory autoimmune disease, with focal lymphocyte infiltration and inflammation in exocrine glands. In SS, lymphocytes selectively target moisture-producing glands, especially the salivary and lacrimal glands, with subsequent loss of their ability to produce saliva and tears. The symptoms can range from dry eyes, dry mouth to joint pain and chronic fatigue that can severely impair quality of life. As a consequence the patients experience a lack of saliva, difficulty in swallowing, hoarseness, sandy-gritty irritation or burning in their eyes. In patients with SS, oral yeast infection may appear, causing unpleasant burning sensation or pain and increased dryness in the mouth. Rapidly progressive dental caries, along with loss of teeth early in the course of disease, resulting from the reduced amount of saliva and its protective effects are found in the majority of patients. Inflammatory complications in the parotid gland, typically occuring in patients with SS, may be the reason for repeated administration of antibiotics, sometimes even hospitalization of patients. Other organs can be involved in the pathogenesis of SS. Patients frequently experience skin dryness and vaginal mucosa dryness. Nephritis develops rarely and usually concurrents coexisting systemic lupus erythematosus (SLE). Severe weakness and simultaneous inflammation of skeletal musles might be an early symptoms of polymyositis. Numbness or tingling as a presentation of neuropathy have been described in patients with SS (6). Moreover, generalized lymphadenopathy, pseudolymphoma, or even lymphoid malignancy may appear in some patients (40).

Two forms of SS are recognized. The first one is the primary Sjögren's syndrome, defined as dry eyes and dry mouth that occurs by itself and is not associated with another autoimmune disorder. Secondary Sjögren's syndrome occurs in the presence of underlying autoimmune connective tissue disease such as rheumatoid arthritis (RA), SLE, scleroderma, polymyositis, primary biliary cirrhosis. Autoantibodies directed against the ribonucleoproteins SSA/Ro (Anti-Ro/SSA) and SS-B/La (anti-La/SSB) are detected with high frequency in patients with Sjögren's syndrome and are recognized as the serological markers for this disease. Rheumatoid factor (RF) occurs less frequently (18).

$\mathrm{SS}$ is regarded as one of the most frequent autoimmune diseases after RA. From the clinical experience it is known that most of the more than 70 well-characterized autoimmune diseases occur more frequently in women. SS is no exception as more than 90 percent of SS syndrome patients 
are women. The exact prevalence is unknown, because many of its milder forms elude diagnosis. The prevalence is estimated to be about $0,6 \%$, according to the criteria used for diagnosis (55). The precise etiology as well as causal therapy is at present unknown and current treatment is mainly palliative (19).

It is supposed that the etiology of SS is multifactorial. Some combination of genetic, hormonal, viral or environmental factors may be involved in the pathogenesis. Female predominance appears to be due to the ability of sex hormones to modulate immunity. Estrogens are known to be natural immune enhancers, whereas androgens are immune suppressors (37). Estrogen deprivation may play a role, as the disease often develops after the menopause. Moreover, Sjögren's syndrome-like disease often develops in estrogendeficient mice (33). The association of Sjögren's syndrome with human leukocyte antigen (HLA)-B8, HLA-DR3, and with the DQA $1 * 0501$ allele supports the idea of genetic predisposition (43). Study from Ivanyi et al. as one of the first confirmed significantly higher frequency of HL-A 8 in patients with SS (16). Viral infection as a possible cause of SS has been frequently considered. No one is sure what agents could start this process in Sjögren's syndrome. Indirect evidence suggest that several viruses may play a role. Research interest has concentrated on the Epstein-Barr virus which has been found in salivary gland biopsies from patient with SS (9). In most cases EBV infects salivary glands leading to a flu-like illness, sometimes with mildly swollen parotid glands. Reactivation of latent EBV occurs more frequently in patients with immunological imbalances or/and during other viral infection which temporarily dampen the immune system (6).

Hepatitis $\mathrm{C}$ virus may be associated with various autoimmune diseases. Generally mild sialadenitis and a lymphocytic infiltrate in the gland was found in HCV-related liver disease, however, the pathological features were different from SS (41). Interestingly, oral lichen planus, which is now also considered likely to be an autoimmune disease, is often associated with the presence of hepatitis C (20). Some authors even propose that HCV infection should be considered an exclusion criterion for the classification of pSS because the virus may be implicated in the development of SS (42).

Other viruses belonging to the group of retroviruses such as HIV and human T lymphotropic virus type I (HTLV-1) have been suggested as one possible trigger in Sjögren's syndrome patients (34). Interestingly, 3 month lasting antiretroviral therapy by using reverse transcriptase inhibitors improved both ocular and oral symptoms and also extraglandular manifestation (fatigue, tender points and arthralgias) in all patients with SS participating the study (47). However, the evidence still remains indirect and viral etiology has never been absolutely confirmed.

Nevertheless, the purpose of this review is to summarize recent findings with the focus on the Toll-like receptors, B cells and their possible involvement in pathogenesis of autoimmune disease such as Sjögren's syndrome.

\section{Toll-like receptors}

Toll-like receptors (TLR) function as sentinels, alerting the innate immune system in the presence of threatening microbial invasion. They are pattern recognition receptors (PRR), recognizing conserved pathogen-associated molecular patterns (PAMPs), which are expressed by organisms ranging from bacteria, protozoa, fungi to viruses. Till now, 10 different TLRs have been detected in humans and 11 have been identified in mice (48). TLR expression is not confined exclusively to macrophages and DC. They can also be expressed by B cells, NK cells, T cells, mast cells, neutrophils, fibroblasts, epithelial cells, keratinocytes, endothelial cells or cardiac myocytes, respectively (35). TLR3, 7, 8 and 9 are located intracellularly in endosomal compartments, while the rest of TLRs are expressed on the cell surface (31).

TLR2 is essential in the recognition of a wide range of microbial molecules representing groups of species such as Gram-positive and Gram-negative bacteria, as well as mycoplasma and yeast. TLR 2 binds a variety of microbial structures, e.g. peptidoglycan and lipoteichoic acid from Gram-positive bacteria, lipoproteins, lipoarabinomannan from mycobacteria etc. TLR2 can form heterodimers with structurally related TLR1 and TLR6, which facilitates microbial recognition. TLR 1 and 6 participate in discrimination of slight differences between triacyl and diacyl lipopeptides and thus cooperate with TLR $2(49,50,51)$.

TLR 3 recognizes double-stranded RNA (dsRNA) as well as a synthetic analog of dsRNA, polyinosine-polycytidylic acid (poly(I:C)). dsRNA is a molecular pattern associated with viral infection and activates the synthesis of type I interferons via a MyD88-independent pathway as discussed below (1).

TLR4 is the receptor for Gram-negative lipopolysaccharide (LPS) and is activated by a very small amount of LPS. Furthermore it was found that TLR 4 is implicated in the recognition of endogenous ligands such as heat shock proteins (HSP 60 and HSP 70) (10).

TLR5 is involved in the recognition of flagellin, the major component of the bacterial flagellar filament, from both Gram+ and Gram- bacteria. TLR 5 plays an important role in the recognition of the microbes at the mucosal surface as it is expressed on the intestinal endothelial cells (30).

TLR7 and TLR8 are phylogenetically and structurally related and are involved in the response to viral infection. Human TLR7 recognizes GU-rich short single-stranded RNA (ssRNA) as well as the imidazoquinoline compounds imiquimod (R837) and resiquimod (R848). Human TLR8 is also involved in the recognition of R848 but surprisingly not R837 (14). TLR7 and TLR8 agonists target various cells and differ in cytokine induction profile. TLR7 agonists activate plasmacytoid DCs (pDCs) and B cells leading to the production of IFN- $\alpha$. TLR8-specific agonists activate myeloid DCs, monocytes and predominantly induce produc- 
tion of proinflammatory cytokines and chemokines, such as TNF-a, IL-12 and MIP-1 $\alpha$ (11). Interestingly, it has been shown that TLR7/8 are implicated in recognizing ssRNA from diverse viruses such as immunodeficiency and influenza viruses $(13,7)$.

TLR9 recognizes specific unmethylated CpG-oligodeoxynucleotides (ODN) sequences that distinguish microbial DNA from mammalian DNA. Bacterial DNA contains unmethylated $\mathrm{CpG}$ motifs, while in mammalian DNA, the cytosine residues of $\mathrm{CpG}$ motifs are highly methylated. In humans, TLR 9 is expressed in B cells and plasmacytoid dendritic cell (PDC), in mice also in the myeloid compartment. Three types of stimulatory ODNs have been described: CpG-A, CpG-B, and CpG-C. CpG-A ODN, also known as 'D'-type, effectively activates NK cells and induces secretion of IFN $\alpha$ in PDC. CpG-B ODN, also known as ' $\mathrm{K}$ '-type was identified first and is involved in the activation of B cells. CpG-B ODN are weak inducers of IFN $\alpha$, however, are very strong Th1 adjuvants and potential B cell response stimulators. $\mathrm{CpG}-\mathrm{C}$ ODN combines the immune effects of CpG-A and -B ODN and trigger B-cell activation similarly to $\mathrm{CpG}-\mathrm{B}$ together with IFN $\alpha$ secretion as $\mathrm{CpG}-\mathrm{A}$ ODN. In addition, NK cells stimulated with CpG-C ODN showed higher cytolytic activity against tumor cell lines. Combination of both immune effects might have broader therapeutic consequences in various tumor types and autoimmune diseases $(2,25)$.

Binding of TLR's ligands triggers signalling via the adaptor protein MyD88, with activation of transcription factors NF- $\kappa \mathrm{B}$ and AP-1, resulting in secretion of inflammatory cytokines such as TNF $\alpha$ and IL 12p40 and upregulation of co-stimulatory molecules (49). Different signalling pathways either dependent or independent on MyD88 were described. In the MyD88-dependent pathway, MyD88 adaptor protein plays a pivotal role. It was shown that MyD88 is used by all TLRs, supported by MyD88-deficient mice model, where no inflammatory cytokines were produced in response to TLR ligands $(52,21)$. Although members of the TLR signal through MyD88, the signalling pathways induced by individual receptors differ. Another adaptor molecule, which is structurally related to MyD88, was identified and termed as TIRAP/Mal (TIR domaincontaining adaptor protein/My D88-adaptor-like) (15). In the experiment with TIRAP/Mal-deficient mice was shown that production of inflammatory cytokine was impaired in the response to TLR 2 and TLR 4 ligands (56). Thus, TI$\mathrm{RAP} / \mathrm{Mal}$ adaptor protein is essential for MyD88 dependent signalling pathway through TLR 2 and TLR 4.

Indeed, the only exception that does not use MyD88 for promoting of downstream signalling is TLR 3. TLR 3 propagates via a MyD88-independent pathway using the adaptor molecule TRIF and thereby induces production of INF- $\beta$ (17). It has been noted that TLR 4 signals via MyD88. However, the hypothesis of additional existence of MyD88-independent components in TLR 4 signalling was proposed. So called TRIF dependent/MyD88-independent pathway can be also used by TLR 4 and leads to activation of the transcription factor IRF 3 and secretion of INF- $\beta$ (in addition to NF- $\mathrm{B}$ ) (22). Accordingly, TLR 3 and 4 signals via MyD88independent pathway to induce INF- $\beta$. Moreover, further search led to the identification of other TRIF-related adaptor molecules named TRAM/TICAM-2. Studies in mice showed that TRAM is implicated in TLR 4-mediated activation of INF-3 and induction of type I INF expression (38). In conclusion, TRAM is important for TRIF dependent/MyD88-independent pathway via TLR 4.

TLRs have a key function in triggering adaptive immune responses to microbes and are probably implicated in inflammatory and autoimmune disorders. Involvement of the TLR-9-MyD88-dependent pathway in the induction of SLE and RA has been described by several research groups (53, $5)$. Thus, innate immunity plays a fundamental role in the initiation of the immune reactions.

\section{B cell Toll like receptors}

An advance in understanding of autoimmune processes has led to the clue, that B cells have additional functions, besides autoantibody secretion. It looks that B cells can present antigen, secrete cytokines and regulate $T$ cells activities independently of antibody production. Thus, application of B cell depletion therapy using rituximab, a chimeric antiCD20 antibody, has improved condition of SLE and RA. Although it would seem that the effect arises from the elimination of autoantibody-secreting B cells, many patients in clinical remission had no decline in serum levels of relevant autoantibodies $(45,39)$.

Various B cells subsets secrete both proinflammatory (TNF $\alpha$, LT $\alpha$, IL-12, IL-6) and suppressive (IL-10) cytokines. The cytokine profile of B cells can also be disturbed by disease, leading to an imbalance of proinflammatory and anti-inflammatory cytokines (29). In patients with multiple sclerosis (MS), the cytokine network was dysregulated. It was evidenced that in MS patients the expression of anti-inflammatory cytokine IL-10 was decreased while the treatment with rituximab reversed the ratio in favor to antiinflammatory cytokines (8).

Experimental data support the idea that autologous nucleic acids, perhaps from necrotic or apoptotic cells, in some circumstances may be stimulatory ligands for TLR7 and TLR9. B cells with BCR specific for antigens complexed with nucleic acids (or specific for the nucleic acids themselves) may internalize the complexes by receptor-assisted endocytosis, making the nucleic acids available for binding to endosome-associated TLR7 or TLR9. Thus, these complexes may be both autoantigens and autoadjuvants $(36,35)$. Indeed, evidence has been presented that engagement of B cell TLR can trigger a humoral immune response. The crucial insight into this problem, demonstrating involvement of BCR and TLR signals in autoantibody production, came from Ann Marshak Rothstein's group. In a model with B cells from AM14 transgenic mice, 
complexes of chromatin and $\mathrm{IgG} 2 \mathrm{a}$ induced production of rheumatoid factor by dual engagement of BCR and TLR9 (28). Moreover in the absence of MyD88, TLR 7 and TLR 9, proliferation of AM14 B cells was abolished (54). Later, a similar effect was reported for TLR7. In this case, the response was more vigorous when IFN $\alpha$ was added. IFN $\alpha$ upregulates TLR7, and is often increased during infections (27).

Some studies have started to deal in more detail with this issue. Study by Hanten et al. compare the effect of TLR7 and 9 on human B cells function by determining gene expression and protein production of several chemokine, cytokine and B cell activation markers. TLR7, 7/8, 9 agonists directly induced the expression of co-stimulatory molecules including CD80, CD86, CD40, CD58 in a similar fashion. Additionaly two receptors were modulated by TLR7, 7/8, 9 agonists. CD23, an important molecule for $B$ cell activation was up regulated, while CD32, resulting in inhibition of B cells was down regulated. The study has demonstrated that B cells were activated by agonists of TLR7 and TLR7/8 in a similar way to the TLR9 agonist (46).

Interestingly, Bourke et al. systematically investigated 10 TLRs mRNA expression profile in normal B cells obtained from human tonsils and malignant $\mathrm{B}$ cells including pre-B cell, Epstein-Barr virus (EBV)- transformed cell lines, Burkitt lymphoma and other neoplastic cell lines. The results have demonstrated that TLR9 and TLR10 were predominantly expressed on human B lymphocytes, similarly to high expression of TLR9 and TLR10 in EBV-transformed B-cell lines, Burkitt lymphoma, follicular lymphoma, and multiple myeloma cell lines. However, pre-B cell lines were negative for TLR9 and TLR10, supporting the theory that expression of TLR9 and TLR 10 correlates with B-cell differentiation and maturation. In result, stimulation through TLR may create a link between chronic infection and pathogenesis of lymphomas (4).

Shlomchik (46) proposed a model of autoimmunity feedback cycle, where the break of tolerance is initiated by recognition of auto-Ags that carry an endogenous TLR ligand such as DNA. Ligation of BCR and TLR leads to presentation of auto-Ag to autoreactive $\mathrm{T}$ cells and activation of T cells with expression of CD40 and IL-21 along with other costimulatory molecules and cytokines. Activated $\mathrm{T}$ cell may then broaden previous autoreactive B cell reaction and help them to enhance clonal expansion, isotype switch, somatic hypermutation, affinity maturation and differentiation into antibody-secreting cells and activation of many other autoreactive $B$ cells.

It seems that engagement of BCR and TLR might be the initial point in breaking tolerance, and the presence of $\mathrm{T}$ cells is required subsequently to generate a fully-developed autoimmune response. However, T cell tolerance must be also breached. The activation of autoreactive $T$ cells can be initiated though APCs, such as DCs and macrophages, which are able to activate naive $\mathrm{T}$ cells. On the other hand, autoreactive B cells that have previously been activated in
T cell-independent/BCR and TLR-dependent way, can activate autoreactive $\mathrm{T}$ cells resulting in boosting and terminal development of autoimmune reaction.

\section{Naive and memory B cells}

Several animal studies have indicated that there is a synergism between TLR and B cells (28). The crosslinking of TLR and BCR in the presence of antigens containing polyclonal activator, such as LPS or unmethylated DNA, might be a critical step in pathogenesis of autoimmune diseases such as systemic lupus erythematosus (24). Mouse naive $B$ cells, compared to human naive $B$ cells, express high levels of TLRs and can be activated by TLR ligands (LPS or CpG) without additional help from T cells or BCR stimulation. In humans, TLRs are expressed at very low levels by naive B cells, until they are stimulated through BCR. In contrast to human naive $B$ cells, human memory B cells constitutively express high levels of TLR2, -6, -7, -9 and -10 (26, 36 ). Triggering via TLR 7 and 9 agonists leads to proliferation and differentiation of human memory B cells into Ig-secreting cells, cytokine production and up-regulation of activation markers for antigen presentation to (autoreactive) $\mathrm{T}$ cells (36). In addition, human memory B cells can be activated with the help of T cells, independently of an antigen (26). Bernasconi et al. proposed that the upregulation of TLR9 expression following BCR triggering cooperates in the activation of naive $B$ cells. In the first step antigen binds to BCR and triggers TLR9 expression followed by internalization of antigen with its TLR9 ligand in the endosomal compartment and interaction with newly synthesized TLR9. CpG DNA has been considered to be a potent stimulant of $\mathrm{B}$ cells, enhancing final differentiation. After stimulation of naive and memory B cell subsets with $\mathrm{CpG}$, anti-Ig and various cytokines, several observations were made. The response of naive and memory B cells did differ. Naive B cells proliferated only when stimulated by $\mathrm{CpG}$, anti-Ig, IL-2 and IL-10, while there was no significant difference in the response of memory B cells either in the presence or in the absence of anti-Ig. It was also shown that naive and memory $\mathrm{B}$ cells proliferation can be induce in the $\mathrm{T}$ independent fashion (3).

This makes the human immune system highly specific, because coupling of TLR 9 and BCR in the absence of $T$ cells enables the naive $B$ cells to be the only ones activated by microbial stimuli. In contrast, constitutive expression of TLR in memory B cells ensures permanent support in antibody production of all memory specificities thereby sustaining serological memory. Thus, a novel role for TLRs in the immune response was suggested $(36,46,26,3)$.

More recently, Ruprecht and Lanzavecchia (44) proposed a model of activation of human naive B cells. According to their findings it seems that three signals are required for optimal activation: Antigen binding to BCR (signal one), specific binding of $\mathrm{T}$ cell receptor (signal two) and engagement of a TLR (signal three). It was shown that 
signal one and two are sufficient for starting initial proliferation of naive $\mathrm{B}$ cells, however, they fail to keep $\mathrm{B}$ cell expansion and proliferation. In one of the experiments, naive B cells were stimulated with anti-IgG, T cell help (CD4+ $\mathrm{T}$ cells in presence of bacterial superantigen TSST) and CpG. After 24 hours all stimuli were removed and then repeatedly added alone or in combination. When added $\mathrm{CpG}$ and $\mathrm{T}$ cell help alone, the response was only partly reestablished. The effective response was reached when stimuli were given together. In conclusion, TLR stimulation, as a third signal, is a critical point in activation of human naive $B$ cells.

A few clinical studies with the focus on Toll like receptors of SS patients exist. Zheng et al. investigated the expression of TLR 7, 8, 9 in peripheral mononuclear blood cells (PMBCs) and the existence of TLR 7 and 9 in minor parotid glands in patients with primary Sjögren's syndrome (pSS). They found that expression of TLR 7 and 9 was upregulated in pSS, while TLR 8 was not. Moreover, TLR 7 and 9 positive cells were detected in the epithelial islands, lymphocytes and ductal epithelial cells of the parotid glands in pSS, and were more frequent than in controls (57). Interestingly, another study by Zheng et al. focused on interferon-regulatory factors (IRF) of the Toll-like receptor family. Expression of IRF 1, 3, and 7 in PMBCs was investigated, and upregulated levels of IRF 1 in patients with pSS compared to controls was demonstrated (58). Kawakami et al. investigated expression of TLRs in labial salivary glands of patients with SS, where TLR 2, 3, 4 and MyD88 were more strongly expressed than in controls and involvement of mitogen-activated protein kinase pathway was suggested (23). Interesting findings came from Manoussakis et al., who focused on TLR 3 expression and possible link to the apoptotic death. In this study, polyI:C-treated salivary gland epithelial cells were found to suffer detachment-induced apoptosis, so-called anoikis. Pro-apoptotic molecules such as Bmf, BimEL and Bax were upregulated, while prosurvival Bcl-2 was downregulated. Finaly, it was found that salivary gland epithelial cells derived from pSS patients were particularly susceptible to TLR-3-induced anoikis than in control group. These activation processes may operate in the epithelial cells of SS patients (32).

\section{Concluding remarks}

Experimental evidence and clinical results demonstrate a key role for B cell and Toll like receptors, mainly TLR 7, 9 and 3 , in the development of systemic autoimmune di-

Tab. 1: Summary of the characteristics of TLRs and their expression on human naive and memory B cells.

\begin{tabular}{|c|c|c|c|c|c|}
\hline TLR & ligands & $\begin{array}{l}\text { cellular } \\
\text { location }\end{array}$ & $\begin{array}{l}\text { adaptor } \\
\text { protein }\end{array}$ & \begin{tabular}{|c|} 
expression \\
of TLR \\
on human \\
memory B cells
\end{tabular} & $\begin{array}{c}\text { expression } \\
\text { of TLR } \\
\text { on human } \\
\text { naive B cells }\end{array}$ \\
\hline TLR-1, 2, 6 & $\begin{array}{l}\text { lipoproteins } \\
\text { peptidoglycans } \\
\text { lipoteichoic acids } \\
\text { zymosan LPS }\end{array}$ & $\begin{array}{c}\text { cell } \\
\text { surface }\end{array}$ & $\begin{array}{l}\text { MyD88 } \\
\text { TIRAP }\end{array}$ & $\begin{array}{c}\text { constitutively } \\
\text { high level }\end{array}$ & $\begin{array}{c}\text { not } \\
\text { detected }\end{array}$ \\
\hline TLR-4 & $\begin{array}{c}\text { LPS } \\
\text { HSP60/70 }\end{array}$ & $\begin{array}{c}\text { cell } \\
\text { surface }\end{array}$ & $\begin{array}{l}\text { MyD88,TIRAP } \\
\text { TRAM, TRIF }\end{array}$ & $\begin{array}{c}\text { not } \\
\text { detected }\end{array}$ & $\begin{array}{c}\text { not } \\
\text { detected }\end{array}$ \\
\hline TLR-5 & flagellin & $\begin{array}{c}\text { cell } \\
\text { surface }\end{array}$ & MyD88 & $\begin{array}{c}\text { not } \\
\text { detected }\end{array}$ & $\begin{array}{c}\text { not } \\
\text { detected }\end{array}$ \\
\hline TLR-3 & dsRNA & $\begin{array}{c}\text { endosomal } \\
\text { compartment }\end{array}$ & TRIF & $\begin{array}{c}\text { not } \\
\text { detected }\end{array}$ & $\begin{array}{c}\text { not } \\
\text { detected }\end{array}$ \\
\hline 2-7/8 & ssRNA & $\begin{array}{c}\text { endosomal } \\
\text { compartment }\end{array}$ & MyD88 & $\begin{array}{l}\text { constitutively } \\
\text { high level }\end{array}$ & $\begin{array}{c}\text { upregulated } \\
\text { through BCR } \\
\text { stimulation }\end{array}$ \\
\hline TLR-9 & $\begin{array}{l}\text { unmethylated } \\
\text { CpG DNA }\end{array}$ & $\begin{array}{c}\text { endosomal } \\
\text { compartment }\end{array}$ & MyD88 & $\begin{array}{l}\text { constitutively } \\
\text { high level }\end{array}$ & $\begin{array}{c}\text { upregulated } \\
\text { through BCR } \\
\text { stimulation }\end{array}$ \\
\hline
\end{tabular}

Legend: MyD88: Myeloid differentiation primary response protein 88; TIRAP: Toll/IL-1 receptor-domain-containing adaptor protein; TRIF: Toll/IL-1 receptor-domain-containing adaptor protein inducing INF- $\beta$; TRAM: TRIF-related adaptor molecule; dsRNA: Double-stranded RNA ; ssRNA: Single-stranded RNA; HSP: Heat shock protein 
seases such as SS, SLE, RA. An overview of hypothetical involvement B cell TLRs is shown in Fig. 1. However, in order to fully understand the exact mechanism leading to SS, further studies focusing on the subject are required. This may provide detailed insight into the pathogenesis of autoimmune disease and could be helpful for future development of a novel therapy.

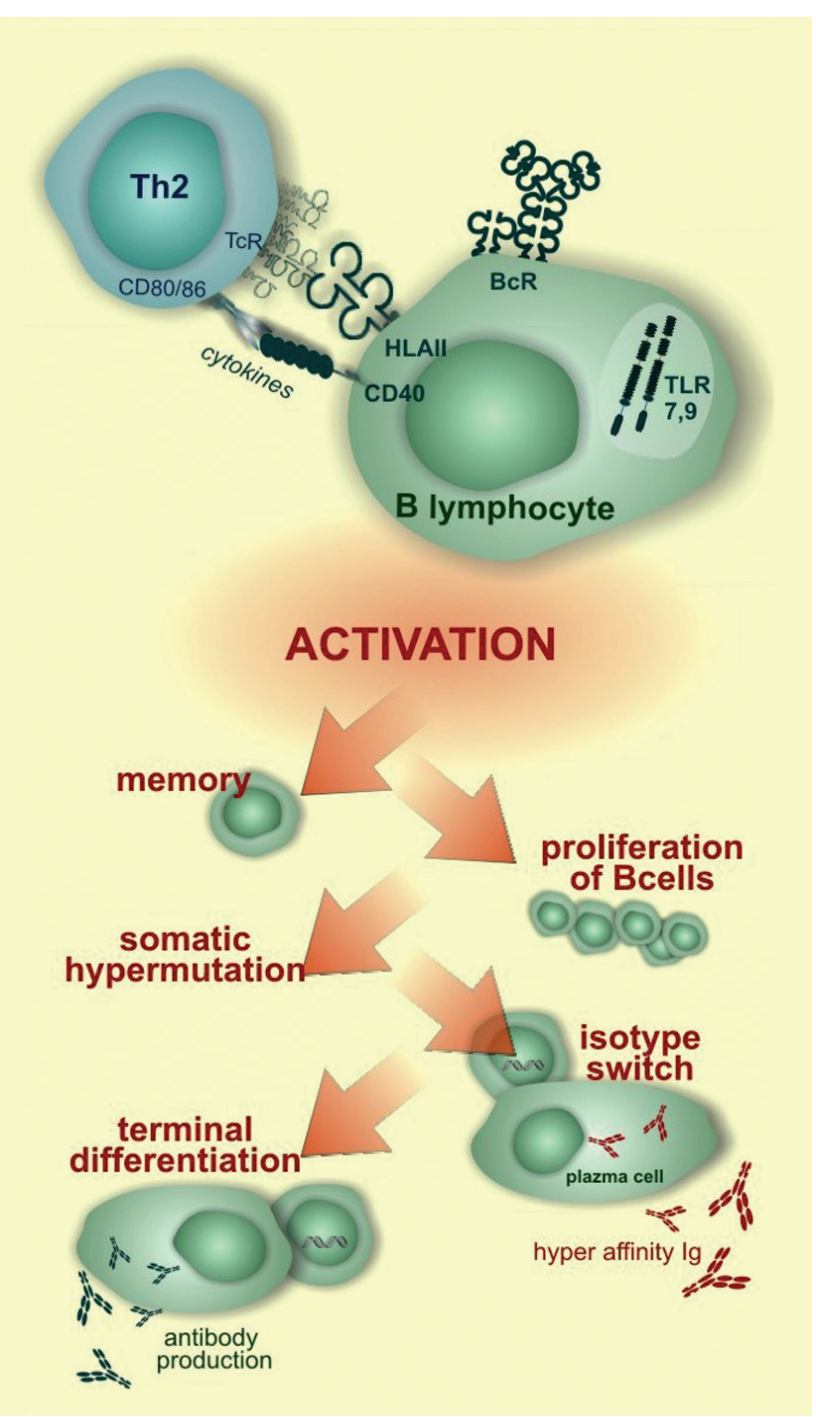

Fig. 1: Three signals model for the induction of the autoimmunity.

Legend: Combined activation through the TLR 7 and 9, the induction of autoantigen to autoreactive BCR and help provided by $\mathrm{TH} 2 \mathrm{~T}$ cells might be necessary for triggering autoimmune reaction. Activation of autoreactive B cells leads to efficient proliferation of B cell, their terminal differentiation into plasma cells and production of large amount of autoantibodies. In addition, this results in somatic hypermutation, ultimating into the hyperaffinity antibodies formation, isotype switching and in the last to the immunological memory formation.

\section{Acknowledgement}

We thank Mrs. Hana Kotlandova for preparing the figures. The work was supported by the grant SVV-2010, No. 260906 Charles University in Prague, School of Medicine Hradec Kralove, partly sponsored by Roche company Junior Research Grant, and Ministry of Education, Czech Republic, project No. MSM0021620812.

\section{References}

1. Alexopoulou L, Holt AC, Medzhitov R, Flavell RA. Recognition of doublestranded RNA and activation of NF-kappaB by Toll-like receptor 3. Nature 2001 Oct 18;413(6857):732-8

2. Ballas ZK, Krieg AM, Warren T et al. Divergent therapeutic and immunologic effects of oligodeoxynucleotides with distinct CpG motifs. J Immunol 2001; 67(9):4878-86.

3. Bernasconi NL, Onai N, Lanzavecchia A. A role for Toll-like receptors in acquired immunity: up-regulation of TLR9 by BCR triggering in naive B cells and constitutive expression in memory B cells. Blood. 2003 Jun 1;101(11):4500-4.

4. Bourke E, Bosisio D, Golay J, Polentarutti N, Mantovani A. The toll-like receptor repertoire of human B lymphocytes: inducible and selective expression of TLR9 and TLR10 in normal and transformed cells. Blood 2003 Aug 1;102(3): 956-63.

5. Boule MW, Broughton C, Mackay F, Akira S, Marshak-Rothstein A, Rifkin IR Toll-like receptor 9-dependent and -independent dendritic cell activation by chromatin-immunoglobulin G complexes. J. Exp. Med. 2004 June 21; 199(12): 1631-1640.

6. Carsons S, Harris EK et al. The new Sjogren's syndrome handbook. 1998; 3-10,71-85.

7. Diebold SS, Kaisho T, Hemmi H, Akira S, Reis e Sousa C. Innate antiviral responses by means of TLR7-mediated recognition of single-stranded RNA. Science. 2004 Mar 5;303(5663):1529-31.

8. Duddy M, Niino M, Adatia F, et al. Distinct effector cytokine profiles of memory and naive human $\mathrm{B}$ cell subsets and implication in multiple sclerosis. J Immunol 2007;178:6092-6099.

9. Fox RI, Pearson G, Vaughan JH. Detection of Epstein-Barr virus-associated antigens and DNA in salivary gland biopsies from patients with Sjögren's syndrome. J Immunol 1986;137:3162-8.

10. Gao B, Tsan MF. Endotoxin contamination in recombinant human heat shock protein 70 (Hsp70) preparation is responsible for the induction of tumor necrosis factor a release by murine macrophages. J. Biol. Chem 2003;278:174.

11. Gorden KB, Gorski KS, Gibson SJ, et al. Synthetic TLR agonists reveal functional differences between human TLR7 and TLR8. J Immunol. 2005;174: 1259-1268.

12. Hanten JA, Vasilakos JP, Riter CL, Neys L, Lipson KE, Alkan SS, Birmachu W. Comparison of human B cell activation by TLR7 and TLR9 agonists. BMC Immunol 2008;9:39.

13. Heil F, Hemmi H, Hochrein H, et. al. Species-specific recognition of single-stranded RNA via toll-like receptor 7 and 8. Science. 2004 Mar 5;303(5663):1526-9.

14. Hemmi H, Kaisho T, Takeuchi O, et. al. Small anti-viral compounds activate immune cells via the TLR7 MyD88-dependent signaling pathway. Nat Immunol. $2002 \mathrm{Feb} ; 3(2): 196-200$

15. Horng T, Barton GM, Medzhitov R. TIRAP: an adapter molecule in the Toll signaling pathway. Nat Immunol $2001 \mathrm{Sep} ; 2(9$

16. Iványi D, Dřizhal I, Erbenová E, et al. HL-A in Sjögren's syndrome. Tissue Antigens. 1976 Jan; 7(1):45-51.

17. Jiang Z, Mak TW, Sen G, Li X. Toll-like receptor 3-mediated activation of NFkappaB and IRF3 diverges at Toll-IL-1 receptor domain-containing adapter inducing IFN-beta. Proc Natl Acad Sci U S A. 2004 Mar 9;101(10):3533-8.

18. Jonsson R, Bowman S, Gordon T. Sjögren's syndrome. In: Koopman W, Moreland L, eds. Arthritis and Allied Conditions - A Text- book of Rheumatology. Philadelphia, USA: Lippincott Williams \& Wilkins, 2005:1681-705.

19. Jonsson R, Bolstad AI, Brokstad KA, Brun JG. Sjögren's syndrome-a plethora of clinical and immunological phenotypes with a complex genetic background. Ann N Y Acad Sci. 2007 Jun;1108:433-47.

20. Kalfus P, Dřízhal I, Živný P. Orální lichen planus a hepatitida C. LKS č.2. 2006 Feb;16:18-21.

21. Kawai T, Adachi O, Ogawa T, Takeda K, Akira S. Unresponsiveness of MyD88 deficient mice to endotoxin. Imunity 1999 Jul;11(1):115-22.

22. Kawai T, Takeuchi O, Fujita T, et al. Lipopolysaccharide stimulates the MyD88independent pathway and results in activation of IRF-3 and the expression of a subset of LPS-inducible genes. J. Immunol 2001 Nov 15;167(10):5887-94.

23. Kawakami A, Nakashima K, Tamai M, et al. Toll-like receptor in salivary glands from patients with Sjögren's syndrome: functional analysis by human salivary gland cell line. J Rheumatol. 2007 May;34(5):1019-26. 
24. Kim WU, Sreih A, Bucala R. Toll-like receptors in systemic lupus erythematosus; prospects for therapeutic intervention. Autoimmun Rev. 2009 Jan;8(3):204-8.

25. Krug A, Rothenfusser $\mathrm{S}$, Hornung $\mathrm{V}$, et al. Identification of $\mathrm{CpG}$ oligonucleotide sequences with high induction of IFN-alpha/beta in plasmacytoid dendritic cells Eur J Immunol 2001;31(7):2154-63.

26. Lanzavecchia A, Sallusto F. Toll-like receptors and innate immunity in B-cell activation and antibody responses. Curr Opin Immunol. 2007 Jun;19(3):268-74.

27. Lau CM, Broughton C, Tabor AS, Akira S, Flavell RA et al: RNA-associated autoantigens activate $\mathrm{B}$ cells by combined B cell antigen receptor/Toll-like receptor 7 engagement. J Exp Med 2005. 202: 1171-7.

28. Leadbetter A, Rifkin IR, Hohlbaum AM Beaudette BC, Shlomchik MJ, MarshakRothstein A: Chromatin-IgG complexes activate B cells by dual engagement of IgM and Toll-like receptors. Nature 2002 416: 603-7.

29. Lund FE. Cytokine-producing B lymphocytes - key regulators of immunity. Curr Opin Immunol 2008 June, 20(3):332-338.

30. Maaser C, Heidemann J, von Eiff C. Human intestinal microvascular endothelia cells express Toll-like receptor 5: a binding partner for bacterial flagellin. J. Immunol 2004;172:5056.

31. Manicassamy S, Pulendran B. Modulation of adaptive immunity with Toll-like receptors. Seminars in Immunology. 2009 Aug;21(4):185-193.

32. Manoussakis MN, Spachidou MP, Maratheftis CI. Salivary epithelial cells from Sjogren's syndrome patients are highly sensitive to anoikis induced by TLR-3 ligation. J Autoimmun. 2010 Nov;35(3):212-8.

33. Mariette X, Gottenberg J-E. Pathogenesis of Sjogren's syndrome and therapeutic consequences. September $2010 \mathrm{Sept}$;22(5)471-477.

34. Mariette X, Agbalika F, Zucker-Franklin D, et al. Detection of the tax gene of HTVL-I in labial salivary glands from patients with Sjögren's syndrome and other diseases of the oral cavity. Clin Exp Rheumatol 2000;18:341-7.

35. Marshak-Rothstein A. Toll-like receptors in systemic autoimmune disease. Nature Rev Immunol 2006. 6: 823-35.

36. Meyer-Bahlburg A, Rawlings DJ. B cell autonomous TLR signalling and autoimmunity. Autoimmun Rev. 2008 Feb;7(4):313-6.

37. Nikolov NP, Illei GG. Pathogenesis of Sjőgren's syndrome. Curr Opin Rheumatol. 2009 Sept;21(5):465-470.

38. Oshiumi H, Sasai M, Shida K, Fujita T, Matsumoto M, Seya T. TIR-containing adapter molecule (TICAM)-2, a bridging adapter recruiting to toll-like receptor 4 TICAM-1 that induces interferon-beta. J Biol Chem. 2003 Dec 12;278(50): 49751-62.

39. Palanichamy A, Barnard J, Zheng B, et al. Novel human transitional B cell populations revealed by B cell depletion therapy. J Immunol. 2009 May 15;182(10): 5982-93.

40. Pariente D, Anaya JM, Combe B, et. al. Non-Hodgkin's lymphoma associated with primary Sjögren's syndrome. Eur J Med. 1992 Oct;1(6):337-42.

41. Pirisi M, Scott C, Fabris C et al. Mild sialoadenitis: a common finding in patient with hepatitis C virus infection. Scand J Gastroenterol 1994 Oct;29(10):940-2.
42. Ramos-Casals M, Mu, Zern PB. Hepatitis C virus and Sjögren's syndrome: trigger or mimic? Rheum Dis Clin North Am. 2008 Nov;34(4):869-84, vii.

43. Reveille JD, Arnett FC. The immunogenetics of Sjogren's syndrome. Rheum Dis Clin North Am. Aug 1992;18(3):539-50.

44. Ruprecht CR, Lanzavecchia A. Toll-like receptor stimulation as a third signal required for activation of human naive B cells. Eur J Immunol. 2006 Apr;36(4): $810-6$

45. Sanz I, Anolik JH, Looney RJ. B cell depletion therapy in autoimmune diseases. Front Biosci 2007;12:2546-2567.

46. Shlomchik MJ. Activating systemic autoimmunity: B's, T's, and tolls. Curr Opin Immunol 2009 Dec;21(6):626-33.

47. Steinfeld SD, Doels P, Van Vooren JP, Cogan E, Appelboom T. Zidovudin in primary Sjögren's syndrome. Rheumatology 1999;38:814-7.

48. Takeda K, Kaisho T, Akira S. Toll-like receptors. Annu Rev Immunol. 2003, $21: 335-76$

49. Takeda K, Akira S. Toll-like receptors in innate immunity. Int. Immunol 2005 ; $17: 1-14$

50. Takeuchi O, Kawai T, Mühlradt PF, et al. Discrimination of bacterial lipoproteins by Toll-like receptor 6 . Int. Immunol. 2001 Jul;13(7):933-40.

51. Takeuchi O, Sato S, Horiuchi T, et al. Cutting edge: role of TLR1 in mediating immune response to microbial lipoproteins. J. Immunol. 2002 Jul 1;169(1):10-4.

52. Takeuchi O, Takeda K, Hoshino K, Adachi O, Ogawa T, Akira, S. Cellular responses to bacterial cell wall components are mediated through MyD88-dependent signaling cascades. Int. Immunol 2000 Jan;12(1):113-7.

53. Viglianti GA, Lau CM, Hanley TM, Miko BA, Shlomchik MJ, Marshak-Rothstein A. Activation of autoreactive B cells by $\mathrm{CpG}$ dsDNA. Immunity $2003 \mathrm{Dec}$ 19(6):837-47.

54. Viglianti GA, Lau CM, Hanley TM, Miko BA, Shlomchik MJ, Marshak-Rothstein A. Activation of autoreactive B cells by CpG dsDNA. Immunity 2003;19(6): 837-847.

55. Vitali C, Bombardieri S, Jonsson R, et al. Classification criteria for Sjőgren's syndrome: a revised version of the European criteria proposed by the AmericanEuropean Consensus Group. Ann Rheum Dis 2002;61:554-8.

56. Yamamoto M, Sato S, Hemmi H, et al. Essential role of TIRAP/Mal for activation of the signaling cascade shared by TLR2 and TLR4. Nature 2002;420: 324-329.

56. Yamamoto M, Sato S, Hemmi H, et al. Essential role of TIRAP/Mal for activation of the signaling cascade shared by TLR2 and TLR4. Nature 2002; 420:324-329.

57. Zheng L, Zhang Z, Yu C, Yang C. Expression of Toll-like receptors 7, 8, and 9 in primary Sjögren's syndrome. Oral Surg Oral Med Oral Pathol Oral Radiol Endod 2010 Jun;109(6):844-50.

58. Zheng L, Yu C, Zhang Z, Yang C, Cai X. Expression of interferon regulatory factor 1, 3, and 7 in primary Sjögren syndrome. Oral Surg Oral Med Oral Patho Oral Radiol Endod 2009 May;107(5):661-8.

Received: 22/11/2010.

Accepted in revised form: $21 / 02 / 2011$.

\section{Corresponding author:}

prof. Jan Krejsek, Charles University in Prague, Faculty of Medicine and University Hospital Hradec Králové, Czech Republic: Department of Clinical Immunology and Allergology; e-mail: krejsek@fnhk.cz 